\title{
Perbandingan Model Tingkat Kepuasan Perwalian Online Mahasiswa Berdasarkan Tahun Masuk di FMIPA Universitas Syiah Kuala
}

\author{
MIFTAHUDDIN $^{1}$, RISANA RACHMATAN ${ }^{2}$, MARLINDAWATI ${ }^{3}$ \\ ${ }^{1}$ Dosen, Program Studi Statistika, FMIPA, Universitas Syiah Kuala, Banda Aceh \\ 2Dosen, Program Studi Psikologi, FK, Universitas Syiah Kuala, Banda Aceh \\ 3Jurusan Statistika, FMIPA, Universitas Syiah Kuala, Banda Aceh
}

\begin{abstract}
ABSTRAK
Tingkatan kepuasan mahasiswa adalah bervariasi untuk setiap tahun masuk Perguruan Tinggi terutama dalam penggunaan sistem perwalian online. Tujuan penelitian ini untuk membandingkan model tingkat kepuasan mahasiswa berdasarkan tahun masuk di FMIPA Universitas Syiah Kuala dengan menggunakan metode regresi logistik ordinal. Dalam penelitian ini digunakan data primer yang berasal dari penyebaran kuesioner pada 135 responden yang merupakan mahasiswa aktif di FMIPA Universitas Syiah Kuala tahun angkatan 2013, 2014 dan 2015. Untuk penelitian ini digunakan 9 variabel prediktor dan variabel respons yaitu: variabel kemudahan, efisiensi, kesalahan, mudah diingat, jenis kelamin, asal daerah, tahun angkatan, IPK, waktu tunggu dan tingkat kepuasan mahasiswa dalam penggunaan sistem perwalian online. Berdasarkan hasil penelitian diketahui bahwa model terbaik adalah model terbaik terdapat pada model tingkat kepuasan mahasiswa angkatan 2013 dengan nilai AIC terkecil yaitu 78,25\% dan ketepatan klasifikasi tertinggi yaitu $80,5 \%$. Dengan satu variabel yang berpengaruh pada taraf signifikan sebesar 0,1 yaitu variabel kesalahan.
\end{abstract}

Kata Kunci: Regresi logistik ordinal, kepuasan pengguna, sistem perwalian online.

\section{PENDAHULUAN}

Perwalian akademik yang dilakukan oleh seluruh mahasiswa dalam perguruan tinggi, perwalian berguna untuk menunjang keberhasilan studi dan perkembangan prestasi mahasiswa dalam perkuliahan. Tidak hanya itu, perwalian juga dilakukan untuk mengawasi dan membimbing mahasiswa secara langsung dengan bertatap muka. Namun Unsyiah telah membuat perwalian tersebut menjadi lebih sederhana dan mudah untuk dilakukan yaitu melalui sistem online. Perwalian online tentu berbeda untuk setiap angkatan, dikarenakan tingkatan studi yang dilalui semakin lama akan semakin sulit. Terutama ketika mahasiswa telah berada pada tahap akhir perkuliahan yaitu menulis tugas akhir.

Oleh karena itu, tingkat kepuasan mahasiswa untuk setiap angkatan sangat penting untuk diketahui. Selain itu, persepsi mahasiswa selaku pengguna (user) sistem sangat penting dalam meningkatkan kualitas sistem perwalian online tersebut. Peneliti tertarik untuk menganalisis perbandingan model tingkat kepuasan mahasiswa perwalian online berdasarkan tahun masuk menggunakan faktor dan metode analisis yang berbeda. Adapun faktor yang digunakan adalah kemudahan, efisiensi, kesalahan, mudah diingat, jenis kelamin, asal daerah, IPK, tahun angkatan, IPK, dan waktu tunggu mahasiswa dalam finalisasi KRS online. Dalam penelitian ini, tingkat kepuasan mahasiswa dikategorikan menggunakan skala ordinal. Dalam artikel ini digunakan regresi logistik ordinal dimana jenis metode ini diharapkan mampu menganalisis hubungan antara variabel respon dengan variabel prediktor, dimana variabel respon bersifat polikotomus dengan skala ordinal (Dobson, 2002). Penelitian ini dilakukan untuk membandingkan model tingkat kepuasan mahasiswa berdasarkan tahun masuk di FMIPA Universitas Syiah Kuala. 


\section{Miftahuddin dkk.}

\section{TINJAUAN PUSTAKA}

Kepuasan adalah elemen terpenting untuk dilihat dalam mengevaluasi suatu produk atau jasa. Ketika pengguna (user) merasakan bahwa jasa sesuai dengan harapan atau bahkan lebih dari harapan, saat itulah pelanggan merasa puas. Proses tersebut dalam layanan jasa harus dievaluasi (Fraering dan Minor, 2013).

Menurut Kotler dan Keller (2012) merefleksikan makna kepuasan sebagai perasaan senang (happy) dan atau kecewa (disappointed) seseorang yang dialami setelah membandingkan antara dua refleksi yaitu persepsi kinerja atau hasil suatu produk dengan estimasinya. Makna kepuasan sebagai upaya pemenuhan sesuatu (produk/jasa) atau membuat sesuatu tersebut menjadi layak/memadai. Rubin dan Chisnell (2008) menjelaskan bahwa pengguna merasa puas terhadap suatu produk, ketika produk telah berada dalam keadaan tanpa halangan, kesulitan, keraguan, tanpa pertanyaan dan bahkan tidak ditemukan rasa frustasi dari pengguna ketika menggunakan produk tersebut. Sebuah sistem berbasis website secara umum dapat dibedakan menjadi empat faktor usability yaitu: learnability, efficiency, memorability dan error (Nielsen, 2012).

\section{MODEL REGRESI LOGISTIK ORDINAL}

Model regresi logistik ordinal (RLO) sebagai pengembangan dari regresi logistik biner (RLB), dimana RLO menganalisa data dengan variabel respon merupakan skala ordinal yang terdiri atas tiga atau lebih kategori. Dalam RLO, model yang digunakan adalah model logit kumulatif, dimana model diperoleh dengan membandingkan peluang kumulatifnya. Peluang kurang dari satu atau sama dengan kategori bergantung ke-j pada $p$ variabel prediktor dinyatakan dalam vektor $X$, ditulis $P(Y \leq j \mid X)$ dengan peluang peluang lebih besar dari kategori bergantung ke- $j$, $P(Y>j \mid X)$ (Hosmer dan Lemeshow, 2000). Peluang kumulatif tersebut dapat ditulis $P(Y \leq j \mid X)$ sebagai:

$$
P(Y \leq j \mid X)=\frac{\exp \left(\beta_{0 j}+\sum_{k=1}^{p} \beta_{k} x_{k}\right)}{1+\exp \left(\beta_{0 j}+\sum_{k=1}^{p} \beta_{k} x_{k}\right)}
$$

dimana, $j=1, \ldots, J$ adalah kategori bergantung (Agresti, 2002).

Untuk kategori dependen (bergantung) pada RLO memiliki urutan, maka model yang dapat digunakan adalah logit multiple bergantung yaitu:

$$
\text { logit }[P(Y \leq j \mid X)]=\theta_{i}+\beta^{T} X_{j} j=1,2, \ldots, J-1
$$

dimana notasi $\theta$ sebagai vektor parameter intersep dan $\beta^{T}=\left(\beta_{1}, \beta_{2}, \ldots, \beta_{p}\right)$ sebagai vektor parameter slope.

1) Estimasi Parameter

Metode yang digunakan untuk estimasi parameter $\beta$ dalam RLO adalah dengan metode Maximum Likelihood Estimation (MLE). Selain itu, metode MLE mampu mengatasi masalah sistem persamaan nonlinear melalui proses iterasi Newton Raphson (Hosmer dan Lemeshow, 2000).

2) Pengujian Signifikansi Parameter

Signifikansi parameter yang telah diduga dari model dapat diketahui dengan melakukan pengujian terhadap parameter tersebut. Adapun uji dilakukan pada koefisien. Terdapat dua macam pengujian yaitu pengujian secara serentak dan pengujian secara parsial.

a. Pengujian secara serentak (simultan) dengan Uji Likelihood Ratio (atau Uji-G)

Pengujian parameter secara bersama-sama dapat dilakukan dengan menggunakan prosedur uji perbandingan kemungkinan (ratio likelihood test). Statistik uji G ini membandingkan model lengkap terhadap model yang hanya dengan konstanta. Berikut adalah rumus yang digunakan untuk membandingkan kedua model:

$G=-2 \ln \frac{\left(\frac{n_{1}}{n}\right)^{n_{1}}\left(\frac{n_{0}}{n}\right)^{n_{0}}}{\Pi_{i=1}^{n} \widehat{\pi}_{i}^{y_{i}}\left(1-\widehat{\pi}_{i}^{\left(1-1-y_{i}\right)}\right)}$

Kriteria keputusan yang diambil adalah tolak $H_{0}$ bila Uji $G>x_{(\alpha, v)}^{2}$ untuk $v$ adalah banyaknya variabel prediktor (Hosmer dan Lemeshow, 2000). 
b. Pengujian secara parsial melalui Uji Wald (Uji-W)

Uji Wald dapat digunakan untuk mengidentifikasi ketika hanya ada satu parameter yang diuji (Kleinbaum dan Klein, 2002). Statistik uji ini adalah:

$Z=\frac{\widehat{\beta}_{k i}}{S E\left(\hat{\beta}_{k i}\right)}$

$\hat{\beta}_{k i}$ adalah penaksir $\beta_{k i}$ dan $S E\left(\hat{\beta}_{k i}\right)$ adalah penaksir galat baku $\beta_{k i}$. Kriteria keputusan Tolak $\mathrm{H}_{0}$, jika $Z^{2}>x^{2}\left(\alpha_{1} 1\right)$ atau menolak $\mathrm{H}_{0}$ jika $P$-Value $<\mathrm{a}$.

\section{PEMILIHAN MODEL TERBAIK}

Alat ukur statistika yang dapat digunakan untuk mengukur kesesuaian model adalah AIC (Akaike Information Criteria). Model regresi terbaik berdasarkan kriteria memiliki nilai AIC terkecil (Widarjono,2007). Hal ini berarti bahwa AIC merupakan kriteria informasi yang dapat digunakan untuk melihat kesesuaian model dimana semakin kecil nilai AIC, maka semakin baik model tersebut menjelaskan data prediksi dengan data sesungguhnya (Nachrowi, 2005). Perhitungan metode ini didasarkan pada pendekatan Maximum Likelihood Estimation (MLE) dengan formulasi AIC yaitu:

$\mathrm{AIC}=e^{\frac{\mathrm{n} \tilde{k}^{n}}{n}}\left(\frac{\sum_{i=1}^{\mathrm{n}} u_{i}^{\mathrm{n}}}{n}\right)$

dimana: $k$ sebagai jumlah parameter dalam model termasuk intercept dan $n$ sebagai jumlah observasi (sampel).

Beberapa kelebihan AIC dibanding metode koefisien determinasi $\left(R^{2}\right)$ diantaranya adalah terutama pada pemilihan model regresi terbaik untuk tujuan estimasi, prediksi, dan peramalan (forecasting), yaitu dapat menjelaskan kesesuaian model dengan data saat ini digunakan dan mengestimasi, memprediksi, dan meramalkan nilai yang terjadi di waktu mendatang beberapa periode (Widarjono, 2007).

\section{METODE ANALISA}

\section{DATA DAN VARIABEL PENELITIAN YANG DIGUNAKAN}

Dalam artikel ini digunakan data primer yang dikumpulkan melalui kuesioner dengan jumlah responden 135 yang terdiri dari angkatan 2013, 2014, dan 2015 di FMIPA Unsyiah. Adapun metode analisis data yang digunakan dalam penelitian ini adalah RLO dimana pengolahan datanya dilakukan dengan software R. Berikut variabel yang digunakan dalam penelitiaan ini seperti Tabel 1 .

Tabel 1. Definisi operasional variabel

\begin{tabular}{|c|c|}
\hline Variabel & Keterangan \\
\hline Kepuasan (Y) & $\begin{array}{l}1=\text { Tidak Puas (Not satisfied); } 2=\text { Kurang } \\
\text { Puas (Less Satisfied); } \\
\text { 3= Puas (Satisfied); } 4=\text { Sangat Puas (very } \\
\text { satisfied) }\end{array}$ \\
\hline Kemudahan $\left(\mathrm{X}_{1}\right)$ & \multirow{4}{*}{$\begin{array}{l}1=\text { Tidak Setuju (Disagree) } \\
2=\text { Setuju (Agree) } \\
3=\text { Sangat Setuju (Strongly agree) }\end{array}$} \\
\hline Efisiensi $\left(\mathrm{X}_{2}\right)$ & \\
\hline Kesalahan $\left(\mathrm{X}_{3}\right)$ & \\
\hline Mudah diingat $\left(\mathrm{X}_{4}\right)$ & \\
\hline Jenis kelamin $\left(\mathrm{X}_{5}\right)$ & 1= Laki-laki (Male) ; 2= Perempuan (Female) \\
\hline Asal daerah $\left(\mathrm{X}_{6}\right)$ & 1= Banda Aceh; 2= Luar Banda Aceh \\
\hline Indeks Prestasi Kumulatif (IPK) $\left(\mathrm{X}_{7}\right)$ & $\begin{array}{l}1=\text { IPK } 2,01-2,75 ; 2=\text { IPK 2,76-3,50; } \\
3=\text { IPK > 3,50 }\end{array}$ \\
\hline Waktu tunggu $\left(\mathrm{X}_{8}\right)$ & $\begin{array}{l}1=\text { Lama }(8-11 \text { hari); } 2=\text { Sedang }(4-7 \text { hari; } \\
3=\text { Cepat }(0-3 \text { hari). }\end{array}$ \\
\hline
\end{tabular}

Adapun alur prosedur yang dilakukan dalam penelitian ini adalah sebagai berikut: 


\section{Miftahuddin dkk.}

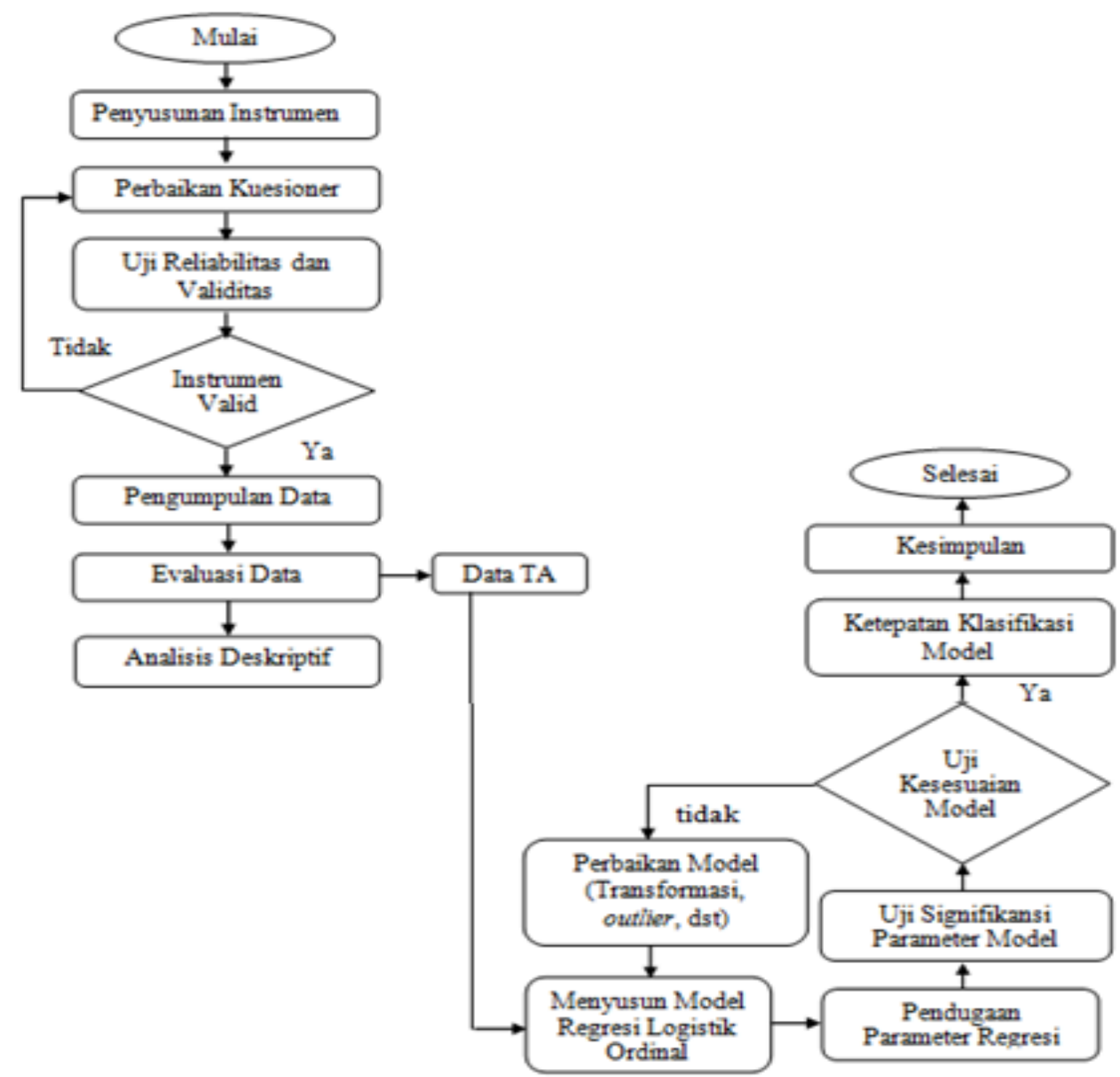

Gambar 1. Flowchart Penelitian Tingkat Kepuasan Perwalian Online

\section{HASIL DAN PEMBAHASAN}

Karakteristik dari variabel tingkat kepuasan perwalian online penting untuk diketahui guna melihat pola dari data yang telah dikumpulkan. Berikut adalah karakteristik data dari variabel tingkat kepuasan mahasiswa terhadap sistem perwalian online $(y)$ yang terdiri dari empat kategori yaitu: Sangat Puas, Puas, Kurang Puas dan Tidak Puas.

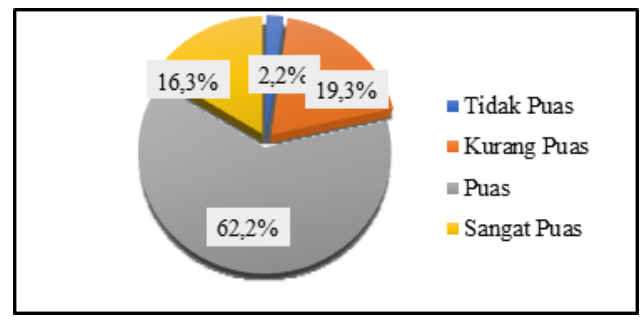

Gambar 2. Pie chart tingkat kepuasan

Gambar 2. menunjukkan tingkat kepuasan mahasiswa terhadap sistem perwalian online pada kategori puas memiliki mayoritas responden terbanyak yaitu $62,2 \%$, kategori kurang puas terhasap sistem perwalian online sebanyak 19,3\%, kategori sangat puas sebanyak 16,3\%, dan kategori tidak puas terhadap sistem perwalian online sebanyak $2,2 \%$.

Sedangkan karakteristik mahasiswa berdasarkan tahun masuk adalah sebagai berikut: 


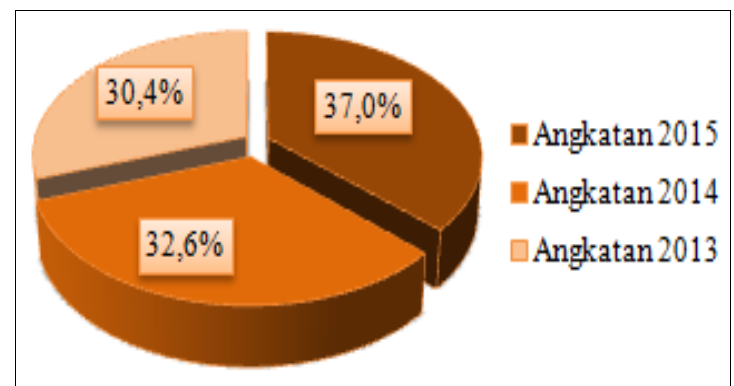

Gambar 3. Pie chart persentase mahasiswa berdasarkan tahun masuk

Berdasarkan Gambar 3. Pie chart menunjukkan persentase jumlah responden berdasarkan tahun masuk, mayoritas responden adalah angkatan 2015 yaitu sebanyak $37 \%$.

\section{PERBANDINGAN MODEL TINGKAT KEPUASAN}

Perbandingan dilakukan dengan melihat nilai AIC dan ketepatan klasifikasi setiap model dari tahun masuk 2013, 2014 dan 2015. Berikut adalah perbandingan model yang dilakukan terhadap tingkat kepuasan mahasiswa berdasarkan tahun masuk.

Tabel 2. Perbandingan model tingkat kepuasan berdasarkan tahun masuk

\begin{tabular}{llll}
\hline Model & Nilai AIC & Ketepatan Klasifikasi & Variabel yang berpengaruh \\
\hline Model 2013 & 78,25 & $80,5 \%$ & $\mathrm{X}_{3}$ (kesalahan) \\
\hline Model 2014 & \multirow{2}{*}{105,43} & $63,6 \%$ & $\begin{array}{l}\mathrm{X}_{1} \text { (kemudahan), } \\
\mathrm{X}_{2} \text { (efisiensi), } \\
\mathrm{X}_{4} \text { (mudah diingat), } \\
\mathrm{X}_{8} \text { (waktu tunggu). }\end{array}$ \\
\hline \multirow{2}{*}{ Model 2015} & 115,30 & $56 \%$ & $\begin{array}{l}\mathrm{X}_{1} \text { (kemudahan), } \\
\mathrm{X}_{4} \text { (mudah diingat). }\end{array}$ \\
\hline
\end{tabular}

Berdasarkan Tabel 2 dapat dilihat bahwa nilai AIC, ketepatan klasifikasi dan variabel yang berpengaruh untuk masing-masing model. Untuk hasil analisa lebih lengkap dapat dilihat pada tabel-tabel berikut ini.

Tabel 3. Anova untuk Model Angkatan 2013

\begin{tabular}{|l|r|r|r|r|}
\hline \multicolumn{1}{|c|}{ Koefisien } & Estimasi & \multicolumn{1}{c|}{ Standar Error } & \multicolumn{1}{c|}{ Z-value } & \multicolumn{1}{c|}{$\operatorname{Pr}(\mathbf{| z |} \mid \mathbf{~}$} \\
\hline Kemudahan 4 & -0.9637 & 3.4845 & -0.277 & 0.7821 \\
\hline Kemudahan 5 & 1.1262 & 3.6596 & 0.308 & 0.7583 \\
\hline Efisiensi 5 & 0.4192 & 1.4176 & 0.296 & 0.7675 \\
\hline Kesalahan 4 & -1.6865 & 1.0629 & -1.587 & 0.1126 \\
\hline Kesalahan 5 & -2.9187 & 1.7553 & -1.663 & 0.0964 \\
\hline Mudah diingat 4 & -2.0385 & 1.7531 & -1.163 & 0.2449 \\
\hline Mudah diingat 5 & -1.8074 & 1.9546 & -0.925 & 0.3551 \\
\hline JK Perempuan & 1.1334 & 1.3122 & 0.864 & 0.3877 \\
\hline Asal Daerah Luar Banda Aceh & 0.3836 & 1.3996 & 0.274 & 0.7841 \\
\hline IPK 3 & 0.6007 & 1.1331 & 0.580 & 0.5960 \\
\hline Waktu Tunggu 2 & 2.7811 & 2.1319 & 1.319 & 0.1920 \\
\hline Waktu Tunggu 3 & 3.0409 & 2.0280 & 1.499 & 0.1338 \\
\hline
\end{tabular}

Dari table 3 diketahui bahwa untuk model 2013 hanya terdapat satu variabel respon yang berpengaruh pada taraf signifikansi 0,1 yaitu variabel kesalahan 5 . 
144 Miftahuddin dkk.

Tabel 3a. Koefisien Threshold Model 2013

\begin{tabular}{|c|r|r|r|}
\hline Parameter & \multicolumn{1}{|c|}{ Estimasi } & Standar Error & \multicolumn{1}{c|}{ Z-value } \\
\hline $1 \mid 2$ & -3.977 & 5.229 & -0.761 \\
\hline $2 \mid 3$ & -1.904 & 5.208 & -0.366 \\
\hline $3 \mid 4$ & 4.032 & 5.140 & 0.784 \\
\hline
\end{tabular}

Tabel 4. Anova untuk Model Angkatan 2014

\begin{tabular}{|l|r|r|r|r|}
\hline \multicolumn{1}{|c|}{ Koefisien } & Estimasi & Standar Error & \multicolumn{1}{c|}{ Z-value } & \multicolumn{1}{c|}{$\operatorname{Pr}(>|\mathbf{z}| \mathbf{)}$} \\
\hline Kemudahan 4 & 2.8079 & 1.5009 & 1.871 & 0.0614. \\
\hline Kemudahan 5 & 3.8126 & 1.6600 & 2.297 & $0.0216^{*}$ \\
\hline Efisiensi 4 & 3.6442 & 2.1189 & 1.720 & 0.0855. \\
\hline Efisiensi 5 & 3.9773 & 2.1350 & 1.863 & 0.0625. \\
\hline Kesalahan 4 & 0.8422 & 1.2380 & 0.680 & 0.4963 \\
\hline Kesalahan 5 & 0.8438 & 1.3909 & 0.607 & 0.5441 \\
\hline Mudah diingat 4 & 2.1349 & 1.7519 & 1.219 & 0.2230 \\
\hline Mudah diingat 5 & 3.5713 & 1.9025 & 1.877 & 0.0605. \\
\hline JK Perempuan & 0.0289 & 1.2752 & 0.023 & 0.9819 \\
\hline Asal Daerah Luar Banda Aceh & 0.4481 & 0.8545 & 0.524 & 0.6000 \\
\hline IPK 2 & -2.3486 & 2.6719 & -0.879 & 0.3794 \\
\hline IPK 3 & -0.9960 & 2.6591 & -0.375 & 0.7080 \\
\hline Waktu Tunggu 3 & -1.7513 & 1.0042 & -1.744 & 0.0812. \\
\hline
\end{tabular}

Untuk model 2014, variabel respon yang berpengaruh secara signifikan pada taraf signifikansi 0,1 ada empat variabel yaitu kemudahan 4, efisiensi 4, 5, mudah diingat 5 dan waktu tunggu 3. Untuk kemudahan 5 signifikan pada taraf signifikasi 0.05

Tabel 4a. Koefisien Threshold Model 2014

\begin{tabular}{|c|r|r|r|}
\hline Parameter & \multicolumn{1}{|c|}{ Estimasi } & Standar Error & \multicolumn{1}{c|}{ Z-value } \\
\hline $1 \mid 2$ & 3.885 & 3.947 & 0.984 \\
\hline $2 \mid 3$ & 5.267 & 4.032 & 1.306 \\
\hline $3 \mid 4$ & 9.358 & 4.205 & 2.225 \\
\hline
\end{tabular}


Tabel 5. Anova untuk Model Angkatan 2015

\begin{tabular}{|l|r|r|r|r|}
\hline Koefisien & Estimasi & Standar Error & \multicolumn{1}{|c|}{ Z-value } & \multicolumn{1}{c|}{$\operatorname{Pr}(>|\mathbf{z}|)$} \\
\hline Kemudahan 4 & 3.8616 & 1.6569 & 2.331 & $0.0198^{*}$ \\
\hline Kemudahan 5 & 5.9641 & 1.9585 & 3.045 & $0.0023^{* *}$ \\
\hline Efisiensi 4 & -5.1019 & 3.6124 & -1.412 & 0.1578 \\
\hline Efisiensi 5 & -5.0301 & 3.7640 & -1.336 & 0.1814 \\
\hline Kesalahan 4 & -0.0998 & 1.0298 & -0.097 & 0.9228 \\
\hline Kesalahan 5 & -0.8507 & 1.2143 & -0.701 & 0.4836 \\
\hline Mudah diingat 4 & 3.3191 & 1.7719 & 1.873 & 0.0611. \\
\hline Mudah diingat 5 & 1.5423 & 1.9952 & 0.773 & 0.4395 \\
\hline JK Perempuan & 0.0489 & 0.7681 & 0.064 & 0.9492 \\
\hline Asal Daerah Luar Banda Aceh & -0.4413 & 0.9079 & -0.486 & 0.6269 \\
\hline IPK 2 & 1.2578 & 1.2206 & 1.030 & 0.3028 \\
\hline IPK 3 & -0.1664 & 1.2857 & -0.129 & 0.8970 \\
\hline Waktu Tunggu 2 & 1.5674 & 1.4027 & 1.117 & 0.2638 \\
\hline Waktu Tunggu 3 & 1.0172 & 1.3066 & 0.779 & 0.4363 \\
\hline
\end{tabular}

Sedangkan model 2015 memiliki dua variabel respon yang berpengaruh secara signifikan pada taraf signifikansi 0,1 yaitu variabel mudah diingat 4. Untuk Kemudahan 4 dan 5 masingmasing signifikan pada taraf signifikasi 0.05 dan 0.01

Tabel 5a. Koefisien Threshold Model 2015

\begin{tabular}{|c|r|r|r|}
\hline Parameter & \multicolumn{1}{|c|}{ Estimasi } & Standar Error & \multicolumn{1}{c|}{ Z-value } \\
\hline $1 \mid 2$ & -1.785 & 3.413 & -0.523 \\
\hline $2 \mid 3$ & 2.604 & 3.485 & 0.747 \\
\hline $3 \mid 4$ & 6.015 & 3.531 & 1.703 \\
\hline
\end{tabular}

masuk pada tahun 2013 memiliki nilai AIC sebesar 78,25 dan ketepatan klasifikasi sebesar $80,5 \%$. Untuk model tingkat kepuasan mahasiswa yang masuk pada tahun 2014 memiliki Pada Tabel 3, 4, dan 5 diketahui bahwa untuk model tingkat kepuasan mahasiswa yang nilai AIC yaitu 105,43 dan ketepatan klasifikasi model sebesar 63,6\%. Sedangkan model untuk tahun masuk 2015 memiliki nilai AIC sebesar 115,30 dan ketepatan klasifikasi sebesar 56\%. Hal ini berarti bahwa model tingkat kepuasan mahasiswa yang masuk pada tahun 2013 adalah model terbaik dan lebih tepat dibandingkan dengan model lainnya.

\section{KESIMPULAN}

Model tingkat kepuasan mahasiswa tahun masuk 2013 di FMIPA Universitas Syiah Kuala memiliki nilai AIC terkecil yaitu 78,25 dan ketepatan klasifikasi sebesar 80,5\%. Model tersebut lebih baik dan tepat dalam menjelaskan data prediksi dengan data sebenarnya dibandingkan untuk tahun masuk 2014 dan 2015.

\section{DAFTAR PUSTAKA}

Dobson, A.J., 2002, An Introduction to Generalized Linear Models, Second Edition. Chapman \& Hall/CRC texts in statistical science series, CRC Press, United States of America. 


\section{Miftahuddin dkk.}

Fraering, M. and Minor, M.S, 2013, Beyond Loyalty: Customer Satisfaction, Loyality, and Fortitude, Journal of Service Marketing, 27(4), 334-344.

Hosmer, D.W. and Lemeshow, S,. 2000, Applied Survival Analysis Regression Modeling of Time to Event Data, John Wiley and Sons. Inc, New York.

Kotler, P. and Keller, K.L. 2012. Marketing Management 14th Edition. Pearson Education Inc, United State of America.

Nachrowi, 2005, Penggunaan Teknik Ekonometri, Jakarta, PT. Raja Grafindo Persada.

Nielsen, J,. 2012, Usability 101: Introduction to usability. Alertbox. http://www,nngroup,com/articles/usability-101-introduction-to-usability/, diakses pada tanggal 28 Maret 2017, pukul 10:56.

Widarjono, A., 2007, Ekonometrika: Teori dan Aplikasi untuk Ekonomi dan Bisnis, Yogyakarta, Ekonisia Fakultas Ekonomi Universitas Islam Indonesia. 